\title{
Percepções das mães sobre a preparação pré- cirúrgica de seus filhos segundo dois modelos
}

\author{
Mothers'perceptions on the pre-surgical preparation \\ of their children according to two models
}

\section{Camilla Volpato Broering ${ }^{[\mathrm{a}]}$, Maria Aparecida Crepaldi ${ }^{[\mathrm{b}]}$}

[a] Mestre em Psicologia da Saúde, Processos Psicossociais e Desenvolvimento Psicológico, Universidade Federal de Santa Catarina (UFSC), Laboratório de Psicologia da Família Saúde e Comunidade (LABSFAC), Florianópolis, SC - Brasil, e-mail: millavolbro@ hotmail.com

[b] Doutora em Psicologia, Docente do Programa de Pós-Graduação em Psicologia da Universidade Federal de Santa Catarina (UFSC), Florianópolis, SC - Brasil, e-mail: crepaldi@cfh.ufsc.br

\section{Resumo}

Este artigo tem por objetivo apresentar uma pesquisa que procurou averiguar quais as mudanças percebidas no comportamento dos filhos por suas mães, decorrentes da preparação para a cirurgia, segundo dois modelos distintos de preparação. A pesquisa foi realizada com 30 participantes, acompanhantes de crianças com idade variando entre 6 e 12 anos, internadas num hospital infantil para a realização de cirurgia eletiva de pequeno porte. Trata-se de uma pesquisa qualitativa, cujo procedimento incluiu duas entrevistas com os acompanhantes: depois da preparação pré-cirúrgica e depois da cirurgia. Segundo as mães, os resultados comprovam que em ambos os grupos as crianças apresentaram reações positivas e apresentaram-se mais calmas, ocorrendo superioridade do $G 2$ em relação ao G1, em alguns aspectos relatados tais como: menos ansiedade, mais felicidade, menos dúvidas e menos dificuldades para dormir. Antes de receberem a preparação, as crianças expressaram indicativos de medo, angústia, além de estresse e ansiedade segundo relato das mães, e, portanto pode-se afirmar que a falta de informação de fato contribui para tal. As implicações práticas dos resultados deste estudo salientam a importância da preparação da criança e da família para as diferentes etapas de um procedimento cirúrgico, que vão desde a decisão de se fazer a cirurgia até os resultados após a sua preparação.

Palavras-chave: Preparação psicológica. Cirurgia na infância. Psicologia pediátrica. 


\begin{abstract}
This article aims at presenting a survey that intended to ascertain the changes in the behavior of children that their mothers perceive, resulting from the preparation for a surgery, according to two distinct models. The survey was conducted with 30 participants, accompanying children aged between 6 and 12 years, admitted to a children's hospital to undergo elective small surgeries. This is a qualitative research, whose procedure included two interviews with the sitters: after pre-surgical preparation and after the surgery itself. According to the mothers, the results prove that in both groups the children had positive reactions and seemed to be calmer, occurring a superiority of G2 compared to G1, reported on some aspects such as less anxiety, more happiness, less uncertainty and less sleep difficulties. Before receiving the preparation, the children expressed feelings indicative of fear, anguish, apart from stress and anxiety, according to what the mothers said, and therefore it can be said that the lack of information actually contributes to this. The practical implications of the results of this study underline the importance of preparing the child and the family for the different steps of a surgical procedure, ranging from the decision to undergo a surgery to the results after the preparation.
\end{abstract}

Keywords: Psychological preparation. Surgery in childhood. Pediatric psychology.

\section{Introduçáo}

Autores clássicos da psicologia pediátrica como Melamed e Siegel (1975), Moix (1996) e Drotar (2002) já reconheciam a importância de se preparar as crianças para todo tipo de procedimento médico, e não apenas para os atos cirúrgicos, como forma de amenizar o estresse existente na situação de hospitalização e, porventura, de cirurgia.

A maioria dos trabalhos recentes (Salmon, 2006; Blount, Lindsey, Cohen \& Cheng, 2006; Uman, chambers, McGrath e Kisely, 2008), que fazem revisões teóricas sobre o tema, ou apresentam técnicas importantes de preparação (Le Roy, Elixso, O’Brien, Tang, Turpin e Uzark, 2003; Duff, 2003), referem-se aos procedimentos médicos em geral, e excluem ou não citam - as cirurgias: alegam a dificuldade de obter medida de eficácia após o ato cirúrgico que seja objetiva, tendo em vista a influência da sedação sobre o comportamento da criança no pós-cirúrgico. Sem contar a preocupação com a eficácia dos procedimentos, que nem sempre é bem avaliada nos estudos realizados (Drotar, 2002).

\section{Os pais e a hospitalização infantil}

A hospitalização éuma situação crítica e delicada na vida de qualquer ser humano, e tem contornos especiais quando se trata de um acontecimento na vida de uma criança, pois implica mudança na rotina de toda família (Zamo, 1997; Peniche \& Chavex, 2000; Faquinello, Higarashi \& Marcon, 2007).

A internação hospitalar traduz-se em experiência bastante difícil para a criança, gerando ansiedade pela sua exposição a um ambiente estressante - o apoio para o enfrentamento desses sentimentos de ansiedade é bastante restrito, de tal forma que uma das únicas fontes de segurança é representada pela presença dos pais (Faquinello \& Collet, 2003).

Beier (1997) afirma que a hospitalização de uma criança normalmente traz consigo um de seus pais, que deixa sua rotina diária, priorizando o filho doente. Desse modo, além dos sentimentos de insegurança, medo da morte e desconfiança, surgem problemas familiares: são os outros filhos que ficam sob o cuidado de terceiros, quando não ficam sós; é a empresa empregadora que não aceita o atestado do filho como justificativa para as faltas; é a falta de recursos financeiros para alimentação ou transporte; e o hospital impondo regras e rotinas que divergem do cotidiano familiar, empregando termos e procedimentos desconhecidos. A situação de adoecimento e hospitalização também é referida como momento de crise para as famílias, devido a uma desintegração temporária-consequentemente, podem surgir ou agravar-se problemas conjugais e adoecimento orgânico e/ou psicológico de outros membros da família (Crepaldi, Rabuske \& Gabarra, 2006). 
Nesse contexto, a permanência dos pais tem como significado a garantia de participação nos cuidados básicos da criança, e sua operacionalização implica o desenvolvimento de ações pelos profissionais de saúde, tais como: orientação e apoio psicológico aos pais quanto aos aspectos específicos do tratamento, medicação e cuidados especiais com a criança, além de orientação quanto à participação nos cuidados básicos ao paciente (Sabatés \& Borba, 2005).

A hospitalização em si já é vista pela criança como ameaçadora e causadora de ansiedade e, dessa forma, tem um impacto sobre o seu comportamento, levando à manifestação de reações adversas como estresse, ansiedade e medo (Crepaldi, 1999; Costa Jr, 1999; Guimarães, 1999; Miyazaki, Amaral \& Salomão, 1999; Salmon, 2006).

Em casos de cirurgia, esta por si só já representa um fator desencadeante de crise, uma vez que a criança se vê exposta a determinados fatores. Quando surge o fator desencadeante - que, nesse caso, é a própria perspectiva cirúrgica -, a criança se vê lançada em direção a fatos que fogem do seu controle e da sua compreensão. Para a criança, a ansiedade não é previsível, pois ela se vê assaltada por elementos desconhecidos, estranhos e assustadores (Trinca, 2003).

Desse modo, é indiscutível o valor da preparação de crianças para procedimentos médicos. Hoje há um consenso em várias áreas das ciências humanas - que têm contato com crianças em via de serem submetidas a intervenções desta natureza - de que algum tipo de intervenção se faz necessária (Crepaldi \& Hackbarth, 2002; Trinca, 2003; Salmon, 2006; Uman et al., 2008; Broering \& Crepaldi, 2008).

Segundo Fighera e Viero (2005), para se tentar obter algum controle sobre o medo e a ansiedade, uma das estratégias é ter sempre a companhia de alguém conhecido. De acordo com Bess d'Alcantara (2008), a preparação deve abranger o pré-operatório, o peri-operatório, o pós-operatório imediato e o pós-operatório tardio. Segundo Crepaldi et al. (2006), a preparação psicológica pré-cirúrgica da criança e dos pais é fundamental, pois lhes possibilita certo grau de controle sobre o desconhecido que a situação cirúrgica representa, pois em geral esta é sentida e percebida como um momento de vulnerabilidade e risco.

Vale ressaltar que a presença da mãe é necessária, mas não contribui para ajudar a criança na situação pré-cirúrgica se não vier acompanhada de uma preparação da criança e da própria mãe. No que diz respeito às informações recebidas, Sabatés e Borba (2005) realizaram um estudo no qual foram entrevistados 50 pais que estavam com seus filhos hospitalizados e 12 enfermeiras que trabalhavam nas unidades de internação pediátrica. Os resultados evidenciaram que os pais não estavam totalmente satisfeitos com as informações recebidas durante a hospitalização dos filhos, pois o que lhes era dito tratava principalmente das regras e rotinas, direitos e deveres, motivos dos procedimentos e participação dos pais no cuidado com o filho hospitalizado. Em geral, os pais solicitam das enfermeiras informações sobre o tempo de hospitalização, evolução da doença, medicação e tratamento do filho.

Outros autores (Skipper \& Leonard, 1968; Moix, 1996; Andraus et al., 2004) afirmam que a transmissão de informação aos pacientes pediátricos é uma das principais técnicas preparatórias. Salientam que, em caso de crianças, em muitas ocasiões e dependendo fundamentalmente da idade, o mais adequado é dar a informação aos pais, posto que são eles quem melhor podem transmiti-la. Conquanto, afirmam que se faz necessário que os pais sejam orientados para saber quais aspectos informar a seus filhos, bem como a maneira de fazê-lo. A falta de informação diante da enfermidade, tanto da parte da criança como de seus pais, acarreta consequências como medo, angústia e depressão em todas as suas expressões, fatores estes que afetam diretamente a recuperação do paciente (Kiyohara et al., 2004).

Em estudo realizado por Jacob e Bousso (2006), constatou-se que o dia da cirurgia é muito aguardado pelos pais. A família teme complicações que possam ocorrer na cirurgia, principalmente a morte da criança. Outra evidência do mesmo estudo, realizado com seis pais de crianças portadoras de cardiopatia congênita, foi o desespero que sentem ao entregarem seus filhos no Centro Cirúrgico. Muitas vezes a mãe encontrava-se sozinha e uma das dificuldades encontradas pela família na fase do conhecimento do diagnóstico era a experiência de conviver, ao mesmo tempo, com a esperança da cura e a possibilidade da morte da criança durante a cirurgia.

Desse maneira considerando que Andraus et al. (2004) indicam que as pessoas que detêm informação sobre situações ou práticas potencialmente aversivas ou ansiogênicas experimentam um maior sentido de controle cognitivo e mantêm a perturbação 
emocional em níveis mais baixos, além de terem seu nível de estresse reduzido, este trabalho tem por objetivo averiguar quais as mudanças percebidas no comportamento dos filhos por suas mães, decorrentes da preparação para a cirurgia, segundo dois modelos distintos de preparação.

\section{Método}

\section{Participantes}

Participaram desta pesquisa 30 acompanhantes (mães ou responsáveis) de crianças com idade variando entre 6 e 12 anos, internadas num hospital infantil para a realização de cirurgia eletiva de pequeno porte. As intervenções cirúrgicas foram: hérnias inguinal e umbilical, amigdalectomia, adenoidectomia e postectomia. As crianças foram divididas em dois grupos, sendo 15 crianças em cada grupo de preparação (G1 e G2). Buscou-se que os grupos fossem pareados por idade, sexo, tipo de cirurgia e experiência prévia com cirurgia. Este procedimento foi adotado para garantir grupos homogêneos.

\section{Instrumentos}

Foram utilizadas duas entrevistas, compostas por questões cujo objetivo foi investigar quais as reações experimentadas pelas crianças após a preparação pré-cirúrgica, nos momentos antes da cirurgia. Vale ressaltar que as mães não receberam instruções para observar as reações das crianças, deixando-as livres para que respondessem às questões espontaneamente. A segunda entrevista foi constituída de questões com o objetivo de obter informações sobre as reações da criança após a cirurgia, ou seja, como havia acordado, o que comentou com a mãe e se teve dúvidas.

\section{Procedimento}

A pesquisa foi realizada em três etapas: $1^{a}$ Etapa: Preparação psicológica pré-cirúrgica: as crianças foram divididas em dois grupos aleatoriamente (G1 e G2). O G1 foi composto por crianças submetidas ao Programa 1: a criança recebia informações verbais, individualmente, sobre o tipo de cirurgia que realizaria. As informações consistiram em contar para a criança todas as etapas pelas quais ela passaria em sua intervenção cirúrgica, incluindo anestesia (cheirinho), tubo de respiração, corte da amígdala ou da hérnia, ou ainda, raspagem da adenoide, curativo e retorno ao quarto. Esse procedimento ocorreu em no máximo 30 minutos. O G2 foi composto por crianças submetidas ao Programa 2: a criança recebia informações individualmente, por meio do uso do kit de preparação pré-cirúrgica, podendo manuseá-los e utilizá-los como desejasse. Desse modo, as informações foram dadas à criança na medida em que ela foi brincando com o boneco. Esse programa teve duração de no máximo 30 minutos. $2^{\mathrm{a}}$ Etapa: Primeira entrevista com as mães após a preparação. $3^{\text {a }}$ Etapa: Segunda entrevista com as mães, após a cirurgia.

\section{Análise de dados}

Foi realizada análise qualitativa dos dados, com o objetivo de propor uma explicação do conjunto de dados reunidos a partir de uma contextualização da realidade percebida.

A entrevista foi gravada e analisada segundo técnicas de análise de conteúdo de Bardin (1977), que se divide em três fases: a pré-análise, a análise e o tratamento dos resultados e interpretação. A pré-análise pressupõe o contato inicial com o material e a escolha deste, realizando leituras do mesmo. Esse processo consiste em "estabelecer contato com os documentos a analisar e em conhecer o texto" (Gabarra, 2005, p. 32). Na fase da análise, os temas foram agrupados e posteriormente houve o tratamento dos dados e sua interpretação.

\section{Resultados}

As respostas das entrevistas foram agrupadas segundo eixos norteadores, nomeados e descritos a seguir, juntamente com os elementos provenientes destes eixos.

\section{Análise dos relatos das máes na primeira entrevista}

A primeira entrevista foi realizada no dia posterior à preparação, dia em que foi realizada a cirurgia. As respostas foram divididas em dois grupos, 
de acordo com o tipo de preparação realizada, para que se pudesse comparar os grupos.

A Tabela 1 apresenta a organização do sistema de categorias para ambos os grupos.

Pode-se constatar que, independentemente do tipo de preparação realizado, esta provocou reações positivas nas crianças, e poucas foram suas dúvidas após a preparação. As respostas não foram mutuamente exclusivas, visto que as mães podem ter dado mais de uma resposta para cada tema.
Em relação aos momentos que antecederam a cirurgia, constatou-se que a ansiedade foi o sentimento relatado com mais frequência pelas mães, ocorrendo pouco mais no G1 do que no G2. Preocupação e fuga também ocorreram no G1, mais do que no G2, embora com pouca frequência. Notou-se que o sentimento de tranquilidade foi relatado pelas mães com maior frequência no G2, embora também tenha sido relatado no G1. Felicidade, fuga e preocupação ocorreram em igual

Tabela 1 - Comparação dos relatos das mães após a preparação, momentos antes da cirurgia de dois grupos distintos de preparação

\begin{tabular}{|c|c|c|c|}
\hline Categorias & Sub-categorias & $\mathrm{G} 1 / \mathrm{F}$ & G2/F \\
\hline \multirow{3}{*}{ Reações à preparação } & Reações positivas & 12 & 13 \\
\hline & Reações negativas & - & 01 \\
\hline & Não fez menção & 03 & 01 \\
\hline \multirow{7}{*}{ Momentos Antes } & Ansiedade & 11 & 06 \\
\hline & Preocupação & 03 & 02 \\
\hline & Tranquilo & 04 & 09 \\
\hline & Fuga & 03 & 01 \\
\hline & Felicidade & 01 & 03 \\
\hline & Fé & 01 & 01 \\
\hline & Medo & - & 02 \\
\hline \multirow{5}{*}{ Dúvidas } & Família & 02 & - \\
\hline & Fome e sede & 01 & 03 \\
\hline & Se vai dar certo & 01 & - \\
\hline & Dor & 01 & - \\
\hline & Não teve dúvidas & 10 & 12 \\
\hline \multirow{4}{*}{ Sono } & Custou a dormir & 02 & 02 \\
\hline & Chorou para dormir & 02 & - \\
\hline & Dormiu bem & 02 & 05 \\
\hline & Não mencionou & 09 & 08 \\
\hline
\end{tabular}

Legenda: $\mathrm{F}=$ frequência de ocorrência de respostas.

Fonte: Elaboração do autor. 
proporção nos dois grupos, e o medo foi a categoria que ocorreu apenas no $\mathrm{G} 2$.

No que diz respeito ao sono, percebeu-se que a maioria das crianças dormiu bem ou não relatou nada sobre o assunto, independentemente do tipo de preparação que receberam. No G2 nenhuma criança chorou para dormir, sendo que foram poucos os relatos de crianças que custaram a dormir. No G1, as crianças apresentaram dificuldade para dormir em igual proporção em que choraram para fazê-lo.

\section{Reaçóes à preparação}

Este eixo diz respeito às percepções que as crianças tiveram após a preparação, tanto no que se refere ao hospital e à internação, como ao procedimento cirúrgico em si e suas consequências, tais como dor, recuperação e presença da rede de apoio.

- Reações positivas: refere-se às percepções favoráveis que as crianças tiveram sobre as informações recebidas durante a preparação, incluindo relatos em que afirmam terem gostado muito da atividade, terem ficado mais calmas após a preparação, terem explicado para suas mães o que ficaram sabendo e até mesmo terem explicado para os colegas de quarto. Muitas crianças pediram para realizar a atividade novamente.

"Ah... ela adoron a atividade, chegon aqui no quarto contando tudo, ai quis dar uma aulinha para os colegas, explicando pra eles... voltou que era só sorriso... gostou mesmo... foi ótimo!"

Constatou-se que das 30 crianças que participaram da preparação, 25 apresentaram reações positivas em relação à mesma. Dentre elas, 12 pertenciam ao G1, e 13 pertenciam ao G2, fato este que não demonstra expressiva diferença entre os grupos.

- Reações negativas: refere-se às percepções negativas que as crianças tiveram sobre as informações recebidas durante a preparação.

"Ele disse que preferia não ter ficado sabendo, disse que ficou com mais medo agora...".

Apenas uma mãe mencionou que seu filho não gostou da preparação.
Ressalta-se que esta criança pertencia ao G2 e que, em contrapartida, no G1 não existiu nenhum relato de reações negativas.

- Não fez menção: diz respeito às mães que não relataram em nenhum momento possíveis comentários que seus filhos tenham feito, alegando que eles não comentaram nada sobre a preparação. "Ele não falou nada, não... chegou no quarto e deitou na cama pra ver TV... e eu também não perguntei...".

Constatou-se que cinco crianças não fizeram comentários sobre a preparação com suas mães. Destas cinco, duas pertenciam ao G1 e uma pertencia ao G2.

\section{Momentos antes da cirurgia}

Este eixo refere-se aos comportamentos emitidos pelas crianças no momento que antecedeu a cirurgia, conforme a percepção e o relato das mães.

- Ansiedade: caracteriza-se por um sentimento difuso e desagradável de apreensão, frequentemente acompanhado por dor de cabeça, tremores, palpitação, choro, nó na garganta e aperto no peito. Normalmente esse sentimento é expresso pelas mães das crianças com o uso de palavras, tais como "preocupado", "agitado" e "nervoso". A ansiedade manifestou-se também por meio do desejo de que a cirurgia ocorresse o mais rápido possível, para que a criança pudesse ir logo para casa.

"Ele está bem agitado agora... quando acordou só falou que queria fazer logo de uma vez, pra voltar pra casa logo...".

Observou-se que nos momentos que antecederam a cirurgia, conforme as mães, 17 crianças foram descritas como ansiosas. Dentre estas, 11 crianças pertenciam ao G1 e 6 crianças pertenciam ao G2. As crianças do G1 assim descritas foram denominadas pelas mães, em sua maioria, como agitadas e nervosas - algumas crianças ainda foram chamadas de ansiosas por fazerem menção a 
ir embora do hospital. No G2, as mães ressaltaram que essa ansiedade estava em grande parte voltada para a vontade das crianças de voltar para casa.

- Preocupação: diz respeito a comportamentos que as crianças emitem diante de uma situação desconhecida, enfatizando o receio de que algo dê errado. "Ah, ele está bem preocupado... é um misto de tudo, né... ficou cabreiro com a camisola que tem que vestir, está dizendo que não vai aguentar de fome, tudo é novo, né...".

Percebeu-se que cinco crianças foram descritas por suas mães como preocupadas. Destas, três crianças pertenciam ao G1, demonstrando preocupação em relação ao pijama cirúrgico e ao jejum. As outras duas crianças pertenciam ao G2, e fizeram-no devido ao fato de "ficar pelado".

- Tranquilo: refere-se a comportamentos emitidos pelas crianças, as quais não demonstraram nenhuma reação negativa à cirurgia, apresentando, por outro lado, bastante confiança e segurança em relação ao procedimento cirúrgico a que seriam submetidas. Demonstraram otimismo por acreditarem que a cirurgia teria êxito e por ser o procedimento o mais adequado a ser feito.

"Ah... ele está bem tranquilo boje... depois que você falou com ele... parece que ele realmente acreditou que vai dar tudo certo, ele sabe que tem que fazer, né...".

Pode-se constatar que 13 crianças foram descritas pelas mães como tranquilas, sendo 4 pertencentes ao G1 e 9 pertencentes ao G2. Essa tranquilidade deve-se em sua maioria ao fato de, após a preparação, as crianças terem entendidoo procedi-mento a que seriam submetidas, e perceberem que seria o melhor a ser feito.

- Fuga: diz respeito a comportamentos que as crianças apresentam para livrar-se da situação que provoca ansiedade ou do próprio hospital. Para isso, agem de várias maneiras, como forma de expressar seu descontentamento em relação ao ambiente inóspito no qual se encontram, ou para defender-se dos sentimentos de insegurança e medo que a colocam em situação de risco constante.

“Ele está mais 'quietão' hoje... não quer conversar, está deitado o tempo todo... sei lá... está estranho... só pode ser da cirurgia que ele está agindo assim...".

Notou-se que, dentre as crianças participantes, quatro apresentaram comportamento de fuga. No G1, três crianças o fizeram, e uma criança do G2. Nos dois grupos, a forma encontrada para demonstrar a fuga foi o isolamento e permanecer mais "quieto".

- Felicidade: consideram-se os comportamentos em que as crianças demonstram ter percepções favoráveis em relação à preparação para o ato cirúrgico, seja por interesse em conhecer o centro cirúrgico, seja pelas consequências do ato cirúrgico, o qual propiciará melhora em relação ao problema.

"Ele está muito feliz... sempre quis conhecer um centro cirúrgico, e depois que você conversou com ele, que ele sabe tudo que tem lá e o que vão fazerer, ele está que é pura felicidade!?'

Constatou-se que quatro crianças foram consideradas como estando felizes, e todas as respostas referem-se a esta felicidade como proveniente da preparação que tiveram, independentemente do grupo a que pertenciam. No G1, uma criança foi descrita pela mãe como feliz, e no G2, três mães descreveram seus filhos dessa forma.

- Fé: comportamentos que as crianças emitem, baseados na crença em Deus, fazendo-as acreditar que, por meio da religião e da crença, a cirurgia será bem-sucedida.

"Ele sabe que vai dar tudo certo, porque é só ter fé em Deus, né... e eu ensinei ele desde pequeno que tudo tem que botar nas mãos do Senhor...". A fé aparece em pequena proporção apenas no G1, sendo que no G2 não houve relatos relacionados à fé.

- Medo: pode traduzir receios de uma situação real (medo do sofrimento advindo de procedimentos realizados no contexto hospitalar, medo de agulha, de soro) ou envolver alguma experiência vivida. 
"Olha, ele acordou bem... está calmo... mas acho que está com medo, sim, quando for para o centro cirúrgico éque vamos ver... porque vai ser a segunda vez que ele veio fazer a mesma cirurgia... a outra não deu certo... e ele é bastante medroso".

O medo apareceu em apenas duas crianças do $G 2$, relacionado ao ato cirúrgico em si. No G1 o medo não apareceu nesse momento, conforme relato das mães.

\section{Dúvidas}

Este eixo inclui respostas que denotam a curiosidade expressa por meio de questionamentos, diante do desconhecido. Sendo assim, as crianças fazem perguntas para suas mães, demonstrando incertezas diante do problema, do procedimento, da frequência da ocorrência de cirurgias iguais às suas e das reações pós-cirúrgicas.

- Família: questionamentos das crianças demonstrando preocupação em relação aos familiares e seus sentimentos.

"Hoje quando ele acordou ele perguntou para mim se eu tava nervosa, e já falou em seguida: 'Você está nervosa, mãe, por que eu não estou nem um pouco?'. Foi engraçado, porque parece que é ele que quer me consolar...".

A dúvida voltada aos familiares ocorreu em pequena proporção apenas no G1.

- Fome e sede: questionamentos que demonstram a curiosidade das crianças em relação ao tempo que precisam ficar sem comer após a cirurgia, ou até mesmo tomar água.

"Ela perguntou pra mim se vai poder comer se tiver fome. Quer saber quanto tempo vai ter que esperar, ela é toda esfomeada...".

Essa dúvida foi constante, tanto no G1 como no G2, ocorrendo em igual proporção.

- Se vai dar certo: questionamentos que expressam insegurança das crianças diante do procedimento, questionando se ele terá êxito.

"Hoje quando acordou ele perguntou pra mim: 'Vai dar tudo certo, né, mãe? Eu não preciso chorar, né?' Ele precisa que eu fique falando isso o tempo todo pra ele, se bem que depois que tu falou com ele, ele já ficou mais sossegado...". Essa dúvida aconteceu apenas no G1 os integrantes do G2 não apresentaram tal dúvida.

- Dor: questionamentos que as crianças fazem para saber se vão ou não sentir dor. "Ela pergunta o tempo todo se vai sentir dor... de resto está tranquila...".

A dúvida em relação à dor ocorreu apenas no G1, sendo que as crianças do G2 não tiveram essa dúvida.

- Não teve dúvidas: ausência de questionamentos das crianças, seja por realmente não existirem, ou por não terem sentido necessidade de fazê-los.

"Ele não teve dúvida nenbuma... com a tua explicação nem teria o que ter dívida mesmo... ele está super bem informado e super seguro em relação a tudo...".

Percebeu-se que a maioria das crianças, de ambos os grupos, não apresentaram dúvidas. No G1, das 15 crianças, 10 não tiveram dúvidas, e no G2,12 crianças não fizeram perguntas de nenhuma ordem para suas mães.

\section{Análise dos relatos das mães na segunda entrevista}

A segunda entrevista foi realizada no dia posterior à preparação, após a realização da cirurgia. Nessa entrevista, as mães também tiveram oportunidade para fazerem comentários a respeito do processo de hospitalização de seus filhos.

As respostas obtidas com essa entrevista foram divididas em dois grupos, de acordo com o tipo de preparação realizada, para que pudesse ser feita uma comparação entre eles, e é dessa forma que os resultados serão apresentados.

A Tabela 2 apresenta a organização do sistema de categorias para ambos os grupos.

\section{Reaçôes após a cirurgia}

Esta categoria respeito às reações que as crianças apresentaram no quarto, após acordarem 
Tabela 2 - Comparação dos relatos das mães após a cirurgia, de dois grupos distintos de preparação

\begin{tabular}{llll}
\hline Categorias & Sub-categorias & G1 & G2 \\
\hline \multirow{3}{*}{ Reações à cirurgia } & Vômito & 08 & 02 \\
& Choro & 05 & 05 \\
& Dor & 06 & 04 \\
& Sonolência & 03 & 03 \\
Não teve reação & 01 & 05 \\
Vômito & 01 & 01 \\
Comida & 02 & 01 \\
Cúvidas & Curativo & 01 & 01 \\
& Cirurgia & 01 & 01 \\
& Ausência da mãe & - & 11 \\
\hline
\end{tabular}

Fonte: Elaboração do autor.

da cirurgia, conforme a percepção e posterior relato de suas mães.

As reações mais frequentes citadas pelas mães foram: choro, vômito, dor e sonolência. O choro, a dor e a sonolência ocorreram em igual proporção tanto no G1 como no G2. O vômito ocorreu com mais frequência no G1. No G1, uma mãe relatou que seu filho não teve nenhum tipo de reação. Por outro lado, no G2, cinco mães relataram o mesmo fato.

"Ah... ele chegou chorando bastante, aí vomitou um pouco, mas logo dormiu...".

"Está com muita dor ele, mas o médico disse que já está medicado, mas ele se queixa bastante”.

\section{Como o filho acordou}

Esta seção se refere aos relatos das mães para descrever a forma como seus filhos acordaram, seus sentimentos, comportamentos e verbalizações. Far-se-á uma descrição separada para cada grupo neste item, devido à grande quantidade de respostas obtidas.

No G1, as mães, na grande maioria, descreveram seus filhos quando acordaram com as seguintes palavras: apavorado, triste, agitado, tonto apenas 3 mães relataram que seus filhos acordaram tranquilos. Dentre os relatos das 12 mães restantes, pôde-se notar que duas crianças foram chorando para o centro cirúrgico, e uma delas não queria ir, por ter visto um colega de quarto voltar da cirurgia chorando. Outra mãe relatou que seu filho considerou a experiência da cirurgia "horrivel', alegando que nunca mais voltaria ao hospital. 5 mães relataram que seus filhos comentaram que não se lembravam de nada - dentre eles, 3 se mostraram abatidos, não querendo comentar nada, e os outros 2 dormiram logo que chegaram ao quarto. "Não, ele não queria falar nada... está do jeito que ele está aí... eu que fiquei mais nervosa... ixi... me deu um calorão... um brancão... na hora que foi e na hora que veio por causa deste sangue... estas coisas né... até pensei que achei que minha pressão ia aumentar muito, né... mas até que estava normal...".

Apenas uma criança se negou a seguir as recomendações médicas, não querendo comer aquilo que a equipe lhe ofereceu. As enfermeiras comentaram que esse comportamento de não adesão à dieta após a cirurgia é muito frequente, e que as crianças que haviam sido preparadas, com exceção de uma, apresentaram boa adesão à dieta e ao tratamento proposto. Por outro lado, seis crianças chegaram ao quarto informando que estavam com sede ou com fome. "Ele acordou bem, só falou que não lembrava de nada... ele disse que só lembra que desceu... e pronto... Ai ele pediu água... aí eu dei um ponco de água e depois ele comeu... e agora ele está melhor...". 
Uma criança estava acompanhada por seu pai, e este não estava no quarto no momento em que ela chegou do centro cirúrgico - portanto, não pôde relatar como seu filho acordou. Houve um caso em que a criança voltou para o quarto apresentando delírios, segundo a mãe: "Ele ficava contando a bistória do elefante, contando elefantes, sei lá eu... o que ele tava falando direito...". Apenas uma criança passou por uma complicação cirúrgica, apresentando reação alérgica a algum produto utilizado na cirurgia - além disso, a criança apresentou reação alérgica ao medicamento administrado diante da primeira reação.

Ainda nesse grupo (G1), uma mãe relatou que seu filho acordou feliz, visto que, durante a cirurgia, para aproveitar o efeito da anestesia, ele pediu para o médico colocar-lhe um brinco na orelha. "Ele está todo feliz, fica só colocando a mão na orelha pra sentir o brinco... só meu filho mesmo...".

No G2, metade das mães relatou que seus filhos voltaram tranquilos. Houve quatro relatos de crianças agitadas, e um relato de criança com tontura. Não houve relatos de crianças tristes ou apavoradas como ocorreu no G1. Cinco mães relataram que seus filhos comentaram que não se lembraram de nada, e estes mesmos dormiram assim que chegaram ao quarto. Nenhuma criança se negou a seguir as recomendações médicas, ou apresentou choro antes de ir para o centro cirúrgico. Quatro crianças chegaram ao quarto, informando que estavam com sede ou fome, e uma criança se mostrou abatida.

Nesse grupo, uma mãe relatou que sua filha percebeu diferença em sua voz logo que chegou ao quarto: "Ela já disse pra mim que parece que está falando mais solto". Uma criança também apresentou delírios: "Ela disse que tava vendo bichinhos que voavam, e eu me matei de rir, porque eu sabia que não podia, nê".

Outra mãe disse que sua filha, ao voltar para o quarto, comentou: "Foi tudo como a moça falou, mãe, nem senti medo porque eu já sabia". Uma mãe comentou que ao voltar para o quarto seu filho estava bravo, e ela sentiu necessidade de apoio familiar, para conseguir acalmá-lo. "Ele gritava tanto que queria morrer, que me odiava, esperneava tanto, que eu tive que ligar pra minha mãe vir me ajudar, porque eu sozinha não ia dar conta dele".

No G2 ocorreram com frequência menções positivas à preparação, menções estas que não foram citadas no G1. Constatou-se que oito mães relataram a atividade de preparação realizada pela pesquisadora, sendo que duas delas comentaram que seus filhos reagiram bem à cirurgia, pois estavam preparadas para as reações que porventura pudessem ocorrer. "Quando ela vomitou, ela já falou na hora que ela sabia que isso podia acontecer.. que tu tinha falado, né... era ela que me acalmava". Dentre estas oito mães, três relataram que a "atividade foi maravilhosa". Dois pais agradeceram muito a realização da atividade, atribuindo ao hospital como um todo o sucesso da cirurgia: "Eu só tenho que agradecer a você, a este hospital incrivel que nos tratou tão bem, aos médicos, à equipe, a esta atividade que você fer. com ele... ele adorou tanto, e duvido ter outro hospital que faça isso com as crianças, toda criança deveria ter isso".

Ainda nesse grupo, ocorreram três relatos de mães que comentaram que elas estavam mais preocupadas que seus filhos, e reforçaram a necessidade de preparação para os pais também, sendo que uma delas lembrou que o médico elogiou sua filha: "Ele disse nunca ter visto uma criança tão tranquila pra fazer a cirurgia... este tipo de atividade tinha que ser feito com os pais, isso sim...".

\section{Dúvidas}

Esta categoria inclui respostas que denotam curiosidade expressa por meio de questionamentos, após a realização da cirurgia. Sendo assim, as crianças fazem perguntas para suas mães, demonstrando incertezas diante do problema, do procedimento e das reações pós-cirúrgicas.

Tanto no G1 como no G2, foi pouca a ocorrência de dúvidas, visto que 23 crianças não apresentaram dúvida de nenhuma ordem.

As dúvidas que ocorreram foram:

- Vômito: apenas uma criança do G1 apresentou tal dúvida, e ao chegar no quarto indagou sua mãe:

"Será que eu vou vomitar, mãe? Eu não estou sentindo nada".

- Comida: três crianças apresentaram esta dúvida, sendo duas no G2 e uma no G1. "A única dúvida que ele teve foi pra saber quando ele ia poder comer".

- Curativo: apenas duas crianças tiveram dúvidas em relação ao curativo, uma de cada grupo de preparação.

"Ah... ele queria ver as amigdalas como ficaram... queria que eu mostrasse eme perguntava... me fezpegar uma lanterna com uma luzinha 
pra ver o curativo, porque queria ver, mas não conseguiu ver nada, tadinho".

- Cirurgia: apenas duas crianças tiveram dúvidas em relação ao procedimento realizado, uma de cada grupo de preparação. "Ela me perguntou há pouco se rasparam mesmo a adenoide dele... acho que ele estava duvidando que tinham feito alguma coisa, porque está sem dor, ainda bem...”.

Com relação à forma como os filhos acordaram após a cirurgia, bem como os comentários finais que as mães fizeram em relação ao processo cirúrgico de seus filhos como um todo, optou-se por realizar uma análise de frequência de ocorrência de palavras. Tais palavras e/ou expressões foram consideradas recorrentes e pareciam traduzir o que elas perceberam e sentiram sobre o processo de hospitalização de seus filhos. Optou-se por tal método considerando-se a gama de combinações possíveis, o que dificulta a construção de subcategorias. Ressalta-se que as palavras foram apresentadas neste trabalho tal qual utilizadas pelas mães. Segue o esquema como forma de visualização do conteúdo descrito anteriormente (Tabela 3).

Pôde-se notar que, no G2, houve considerável diferença entre os comentários das mães após a cirurgia, tanto no que diz respeito à forma como seus filhos acordaram como em relação ao procedimento de preparação realizado com eles. Constata-se que, no G1, a maioria das mães se absteve de fazer comentários em relação à preparação, fato este que não ocorreu no $G 2$, no qual as mães se sentiram motivadas para expor suas opiniões, fazer agradecimentos e comentários.

\section{Discussáo}

Constatou-se que ambos os programas de preparação foram eficazes na diminuição do estresse pré-cirúrgico, independentemente de qual for o programa, segundo relato das mães.

Porém, na primeira entrevista com as mães, ao se fazer um comparativo entre G1 e G2, percebeu-se que as crianças do G2 estavam mais tranquilas após a preparação, e apresentaram menos ansiedade. Assim, pode-se hipotetizar que o G2 teve melhores resultados. Segundo as mães, em ambos os grupos as crianças apresentaram reações positivas, apresentando-se mais calmas - ocorreu uma leve superioridade do G2 em relação ao G1 em alguns aspectos relatados, tais como: menos ansiedade, mais felicidade, menos dúvidas e menos dificuldades para dormir.

Pode-se afirmar que a falta de informação de fato provoca medo, angústia, além de estresse e ansiedade, visto que, antes de receberem a preparação, as crianças expressaram tais indicadores segundo relato das mães. A importância das informações é reforçada por Kiyohara et al. (2004), que mediram a ansiedade dos pacientes já informados sobre a cirurgia no dia anterior à mesma e concluíram que o conhecimento pode reduzir o estado de ansiedade. As informações, quanto mais específicas, melhor preparam a criança, reduzindo sua ansiedade diante da cirurgia.

Em relação ao pós-cirúrgico, conforme entrevista com as mães, puderam se observar semelhanças entre os dois grupos, como as consequências dos efeitos da anestesia. Vale ressaltar que tais efeitos da anestesia são imprevisíveis e fogem do controle da preparação psicológica pré-cirúrgica. No entanto, pôde-se notar que, no G2, houve considerável diferença entre os comentários das mães após a cirurgia, tanto no que diz respeito à forma como seus filhos acordaram, como em relação ao procedimento de preparação realizado com eles. No G1, a maioria das mães se absteve de fazer comentários em relação à preparação.

No que diz respeito às reações quando a criança acordou, nota-se que nenhuma reação fugiu ao esperado - apenas uma criança teve uma reação alérgica, o que não tinha nenhuma relação com a preparação em si. Outro caso foi de uma criança que não queria ir para o centro cirúrgico, por ter visto o colega do quarto voltar da cirurgia chorando, o que pode prejudicar os resultados da preparação, visto que as crianças voltam para o mesmo quarto em que outras crianças estão esperando para ir para o centro cirúrgico, e isso se torna uma variável interveniente considerável.

Uma questão relacionada ao pós-cirúrgico refere-se ao fato de que as crianças enfrentaram as reações da cirurgia, pois se lembraram dos momentos vividos na preparação, em que haviam sido informadas sobre tal, o que as deixou mais tranquilas. Esse enfrentamento foi observado na forma como as crianças verbalizavam sobre suas reações de maneira tranquila, e explicavam que sabiam o que 
Tabela 3 - Comparação dos relatos das mães após a cirurgia, de dois grupos distintos de preparação

\begin{tabular}{|c|c|c|}
\hline Como acordou depois da cirurgia & $\begin{array}{c}\text { G1 } \\
\text { F/R** }\end{array}$ & $\begin{array}{c}\mathrm{G} 2 \\
\mathrm{~F} / \mathrm{R}^{* *}\end{array}$ \\
\hline Agitado & 06 & 04 \\
\hline Apavorado & 03 & - \\
\hline Delírios & 01 & 01 \\
\hline Feliz & 01 & - \\
\hline Triste & 02 & - \\
\hline Tranquilo & 03 & 07 \\
\hline Não viu chegar & 01 & - \\
\hline Sede & 02 & 01 \\
\hline Fome & 06 & 02 \\
\hline Abatido & 02 & 01 \\
\hline Não aceita recomendação & 01 & - \\
\hline Não lembra & 01 & - \\
\hline \multicolumn{3}{|l|}{ Comentários } \\
\hline Preparada para a reação & - & 03 \\
\hline Informação & 01 & 05 \\
\hline Atividade maravilhosa & - & 04 \\
\hline Agradecimento & - & 03 \\
\hline Lembrou da preparação & 01 & 03 \\
\hline Necessidade de apoio & - & 01 \\
\hline Preparação para pais & 01 & 03 \\
\hline Comentário do médico & 01 & 01 \\
\hline
\end{tabular}

Legenda: ** Frequência de respostas.

Fonte: Elaboração do autor.

poderia ocorrer após a cirurgia, pois participaram da preparação para a mesma. Em relação às reações pós-anestésicas, o papel da preparação é informar para que as crianças não se surpreendam, visto que não há como se evitar essas reações e impedir que aconteçam.

Assim, Peniche e Chaves (2000) pontuam que a cirurgia e a anestesia são situações impostas pela vida, que exigem da criança um enfrentamento. É possível que a antecipação desses eventos desencadeie sentimentos que, influenciados pelas diferenças individuais, resultarão em comportamentos peculiares de ajustes cuja finalidade é enfrentar o estresse e a ansiedade provocados por esse evento.

Fica evidente que, quando uma criança adoece, geralmente ela se sente fragilizada e temerosa, necessitando de cuidados especiais, proteção, carinho e confiança. Quando os pais estão presentes e atendem às necessidades da criança, esses sintomas podem ser amenizados, mesmo que a equipe de saúde não estabeleça com ela uma interação satisfatória, como mostram os resultados de Skipper e Leonard 
(1968). Quando, porém, os pais estão ausentes ou por algum motivo não podem atender à criança, é imprescindível que a equipe de saúde possa fazê-lo, sob pena de aparecerem reações de não aceitação de sua condição e revolta.

Sabatés e Borba (2005) afirmam que os pais não estão, na maioria das vezes, totalmente satisfeitos com as informações recebidas durante a hospitalização do filho. Crepaldi (2006) indica que a parceria entre equipe e pais tem se mostrado muito eficaz nos cuidados à criança, além de beneficiar os pais, que atendem a criança e constituem também um segmento que necessita de atenção. Muitas vezes a ansiedade que os filhos sentem é reflexo da ansiedade de seus pais. Desse modo, é importante que os pais estejam conscientes de que a ansiedade dos filhos está em boa parte na dependência de seu comportamento. Instruções e atenção mínimas que os pais recebem são fundamentais para ajudar a criança a enfrentar a situação.

Assim, fica evidente que a criança que pode acompanhar o que se passa com ela, considerando-se a faixa etária, pode tranquilizar-se e tornar-se mais colaboradora com os procedimentos pós-cirúrgicos e necessidade da cirurgia, mesmo que lhe deixe marcas, como foi verificado no estudo de Skipper e Leonard (1968). Andraus et al. (2004) indicam que as pessoas que detêm informação sobre situações ou práticas potencialmente aversivas ou ansiogênicas experimentam um maior sentido de controle cognitivo e mantêm a perturbação emocional em níveis mais baixos, bem como têm seu nível de estresse reduzido.

\section{Consideraçóes finais}

O pré-operatório costuma desencadear muita ansiedade, quer pelo sofrimento do próprio paciente, quando este já estiver acometido pela doença, quer pelo contato direto com outras pessoas que se encontram no mesmo ambiente de espera, sem contar a inatividade peculiar à situação, exames complementares, separação do paciente de sua família e ambiente, além de outras preocupações que eventualmente a pessoa apresenta.

Neste estudo, as mães também elucidaram que seus filhos demonstraram medo, ansiedade e dúvidas diante da necessidade da cirurgia. Do mesmo modo, estas também demonstraram estresse, preocupação e medo, de acordo com suas falas. Segundo Zamo (1997), quando a criança fica doente, o estresse envolve todos da família, que passa por um período de medo, insegurança e sensação de que perderá o controle sobre os cuidados e a educação da criança doente. A hospitalização em si já é vista pela criança como ameaçadora e causadora de ansiedade e, dessa forma, tem um impacto sobre seu comportamento, levando à manifestação de reações adversas como o estresse, ansiedade e medo (Costa Jr., 1999; Guimarães, 1999; Myazaki et al., 1999).

Neste estudo, notou-se que é conspícua a preparação, independentemente da forma como é feita, pois se mostra eficaz na redução do estresse e da ansiedade de crianças a serem submetidas a cirurgias eletivas. Desde que seja aplicada por profissional conhecedor da área, a preparação provoca efeitos positivos, tais como melhor adesão a tratamento pós-cirúrgico e estratégias de enfrentamento. Também é correto afirmar que é válido e necessário fazer uma preparação pré-cirúrgica, pois ela é profícua para a hospitalização e para a cirurgia, e há indícios de que o seja para a recuperação também.

As famílias não se sentem satisfeitas com as informações recebidas, o que acaba gerando incertezas e preocupações. Dessa forma, pais não preparados e sem informação não estão disponíveis para transmitir as informações adequadas e necessárias para seus filhos, de modo que estes fiquem tranquilos e conhecedores do procedimento cirúrgico a que serão submetidos. Por vezes, a intenção de fazer isso existe, mas nem sempre ela é consolidada, pois ou os pais sabem pouco ou quase nada sobre o que deve ser informado, ou baseiam suas informações em suas próprias representações, fator este que, porventura, pode confundir as crianças, ou até mesmo assustá-las mais do que o necessário para o procedimento em questão.

Desse modo, nota-se a necessidade de uma preparação psicológica eficiente, detalhada e em linguagem simples, de acordo com o grau de compreensão e as particularidades de cada criança. Nesse caso, a preparação de forma individual torna-se mais personalizada e efetiva.

Em suma, é importante afirmar que a preparação psicológica pré-cirúrgica é necessária e eficaz, independentemente de qual metodologia é usada, visto que, por mais simples que seja, sempre produz efeitos positivos e promove estratégias de enfrentamento diante da situação imposta. 
Espera-se, porém, que esta pesquisa acrescente resultados relevantes para a produção científica da área, no sentido não só de diminuir a insuficiência metodológica relacionada ao fornecimento de informações precisas acerca dos efeitos da intervenção psicológica sobre o repertório comportamental do indivíduo hospitalizado, mas também de subsidiar intervenções nesse contexto. Assim, procura-se auxiliar profissionais que atuam no campo da psicologia da saúde a descrever e analisar comportamentos de crianças expostas a procedimentos médicos, de modo a intervir na redução do estresse que acomete aquelas que passam por situações de cirurgia.

Diante das situações relacionadas à saúde da criança e do adolescente, é fundamental uma abordagem multiprofissional que envolva também os aspectos psicológicos da criança/adolescente e suas famílias. É necessário que os profissionais da saúde estejam sensibilizados para os aspectos que transcendem o tratamento médico, pois os resultados do tratamento e as intervenções podem ficar comprometidos se não se considerarem esses aspectos.

Assim, a implementação de serviços de atendimento no hospital deve considerar um planejamento ambiental da instituição para que possam ser efetuadas orientações em relação ao desenvolvimento psicológico da criança. Há necessidade de compreensão da relação entre o paciente e o ambiente em que são dispensados os cuidados com o tratamento.

\section{Referências}

Andraus, L. M. S., Minamisava, R. F., \& Munari, D. B. (2004). Comunicação com a criança no pré-operatório. Pediatria Moderna, 40(6), 242-246.

Bardin, L. (1977). Análise de conteúdo. Lisboa: Edições 70.

Beier, S. (1997). Desenvolvimento da atenção integral à criança com fibrose cística. In R. B. Ceccim, \& P. R. A. Carvalho (Org.). Criança hospitalizada: Atenção integral como escuta a vida. Porto Alegre: Ed. da UFRGS.

Bess d'Alcantara, E. (2008). Criança hospitalizada: O impacto do ambiente hospitalar no seu equilíbrio emocional. Revista Virtual de Psicologia Hospitalar e da Saúde, 3(6), 38-55.
Blount, R. L., Lindsey, T. P., Cohen, L., \& Cheng, P. S. (2006). Pediatric procedural pain. Behavior Modification, 30(24), 23-49.

Broering, C. V., \& Crepaldi, M. A. (2008). Preparação psicológica para a cirurgia em pediatria: Impotância, técnicas e limitações. Paidéia, 18(39), 61-72.

Crepaldi, M. A. (1999). Hospitalização na infância: Representações sociais da família sobre doenças e a hospitalização de seus filhos. Taubaté, SP: Cabral Editora Universitária.

Crepaldi, M. A., \& Hackbarth, I. D. (2002). Aspectos psicológicos de crianças hospitalizadas em situação pré-cirúrgica. Temas em Psicologia da SBP, 10(2), 99-112.

Crepaldi, M. A., Rabuske, M. M., \& Gabarra, L. M. (2006). Modalidades de atuação do psicólogo em psicologia pediátrica. In M. A. Crepaldi, B. M. Linhares, G. B. Perosa, (Org.). Temas em psicologia pediátrica (pp. 13-55). São Paulo: Casa do Psicólogo.

Costa Jr., A. L. (1999). Psicooncologia e manejo de procedimentos invasivos em oncologia pediátrica: Uma revisão de literatura. Psicologia: Reflexão e Crítica, 12(1), 107-118.

Drotar, D. (2002). Enhancing reviews of psychological treatments with pediatric populations: Thoughts on next steps. Journal of Pediatrics Psychology, 27(2), 167-176.

Duff, A. J. A. (2003). Incorporating psychological approaches into routine paediatric venepuncture. Archieves Disease Children, 88(10), 931-937.

Faquinello, P., \& Collet, N. (2003). Vínculo afetivo mãe/ criança na unidade de alojamento conjunto pediátrico. Revista Gaúcha de Enfermagem, 24(3), 294-304.

Faquinello, P., Higarashi, I. H., \& Marcon, S. S. (2007). $\mathrm{O}$ atendimento humanizado em unidade pediátrica: Percepção do acompanhante da criança hospitalizada. Texto e Contexto-Enfermagem, 16(4), 619-616.

Fighera, J., \& Viero, E. V. (2005). Vivências do paciente com relação ao procedimento cirúrgico: Fantasias e sentimentos mais presentes. Revista Brasileira de Psicologia Hospitalar, 8(2), 51-63.

Gabarra, L. M. (2005). Crianças hospitalizadas com doenças crônicas: A compreensão da doença. Dissertação de Mestrado em Psicologia da Universidade Federal de Santa Catarina, Florianópolis. 
Guimarães, S. S. (1999). Psicologia da Saúde e doenças crônicas. In R. R. Kerbauy (Org.). Comportamento e saúde: Explorando alternativas (pp. 22-45). Santo André, SP: ARBytes.

Jacob, Y., \& Bousso, R. S. (2006). Validação de um modelo teórico usado no cuidado com a família que tem um filho com cardiopatia. Rev Esc Enfermagem USP, 40(3), 374-380.

Kiyohara, L. Y., Kayano, L. K., Oliveira, L. M., Yamamoto, M. U., Inagaki, M. M., Ogawa, N. Y. et al. (2004). Surgery information reduces anxiety in the preoperative period. Rev Hosp Clín Fac Med São Paulo, 59(2), 51-56.

Le Roy, S., Elixson, E. M., O’Brien, P., Tong, E., Turpin, S., \& Uzark, K. (2003). Recommendations for preparing children and adolescents for invasive cardiac procederes. Circulation: Journal of the American Heart Association, 108(20), 2550-2564.

Melamed, B., \& Siegel, L. (1975). Reduction of anxiety in children facing hospitalization and surgery by use of filmed modelling. Journal of Consulting and Clinical Psychology, 43(4), 511-521.

Moix, J. (1996). Preparación psicológica para la cirurgia en pediatria. Archivos de Pediatria, 47(4), 211-217.

Miyazaki, M. C. O., Amaral, V. L. A. R., \& Salomão, J. B. (1999). Asma na infância: dificuldades no manejo da doença e problemas comportamentais. In R. R. Kerbauy (Org.). Comportamento e saúde: Explorando alternativas (pp. 99-118). Santo André, SP: ARBytes.

Peniche, A. C. G., \& Chaves, E. C. (2000). Algumas considerações sobre o paciente cirúrgico e a ansiedade. Revista Latino-Americana de Enfermagem, 8(1), 45-50.

Sabatés, A. L., \& Borba, R. I. H. (2005). As informações recebidas pelos pais durante a hospitalização do filho. Revista Latino-Americana de Enfermagem, 13(6), 963-973.

Salmon, K. (2006). Preparing young children for medical procedures: Taking account of memory. Journal of Pediatric Psychology, 31(8), 859-861.

Skipper, J. K., \& Leonard, R. C. (1968). Children, stress and hospitalization: A field experiment. Journal of Health and Social Behavior, 9(4), 274-287.
Uman, L. S., Chambers, C. T., McGrath, P. J., \& Kisely, S. (2008). A systematic review of randomized controlled trials examining psychological interventions for needle-related procedural pain and distress in children and adolescents: an abbreviated Cochrane Review. J Pediatr Psychol, 33(8), 842-856.

Trinca, A. M. T. (2003). A intervenção terapêutica breve e a pré-cirurgia infantil: $\mathrm{O}$ procedimento de desenhos-estórias como instrumento de intermediação terapêutica. São Paulo: Vetor.

Zamo, C. G. S. (1997). O cuidado: terapia de Enfermagem na Pediatria. In R. B. Ceccim \& P. R. A. Carvalho (Org.). Criança hospitalizada: Atenção integral como escuta a vida. Porto Alegre: Ed. da UFRGS.

Recebido: 06/10/2009

Received: 10/06/2009

Aprovado: 07/12/2009

Approved: 12/07/2009 